\title{
ANALISIS EFEKTIVITAS DAN EFEK SAMPING PENGGUNAAN ANTIHIPERTENSI PADA PASIEN GAGAL GINJAL KRONIK RAWAT INAP DI RSUP Dr. WAHIDIN SUDIROHUSODO
}

\author{
Restuyani Paranoan ${ }^{1,3}$, Marianti A.Manggau ${ }^{1}$, Hasyim Kasim², M Natsir Djide ${ }^{1}$, Subehan Lallo ${ }^{1}$, \\ Yulia Yusrini Djabir ${ }^{1}$ \\ ${ }^{1}$ Fakultas Farmasi, Universitas Hasanuddin, Makassar \\ ${ }^{2}$ Departemen IImu Penyakit Dalam, Fakultas Kedokteran, Universitas Hasanuddin, Makassar \\ ${ }^{3}$ Puskesmas Lansot, Tomohon
}

Kata Kunci :

Gagal Ginjal Kronik, Antihipertensi, Efektivitas, Efek Samping

\section{Masuk 21-01-2019 \\ Revisi 21-01-2019 \\ Diterima 21-01-2019}

Korespondensi

Marianti A Manggau winati04@yahoo.co.id

Copyright

(C) 2019 Majalah Farmasi Farmakologi Fakultas

Farmasi · Makassar

Diterbitkan tanggal 30-04-2019

Dapat Diakses Daring Pada:

http://journal.unhas.ac.id /index.php/mff

\section{ABSTRAK}

Sebagian besar pasien penyakit ginjal stadium akhir (ESRD) yang menyebabkan hemodialisis, dapat mengalami hipertensi. Penelitian ini bertujuan untuk menganalisis efektivitas dan efek samping penggunaan antihipertensi amlodipin tunggal dan kombinasi amlodipin dengan telmisartan, dan kombinasi amlodipin dengan Valsartan pada pasien gagal ginjal kronik selama rawat inap di RSUP Dr. Wahidin Sudirohusodo Makassar. Penelitian ini dilaksanakan di ruangan rekam medik RSUP Wahidin Sudirohusodo selama periode September sampai oktober 2018. penelitian ini merupakan penelitian observasional noneksperimental. pengambilan data dilakukan secara retrospektif. pengambilan data berdasarkan rekam medik pasien gagal ginjal kronik (ESRD) yang mendapat terapi obat antihipertensi amlodipin tunggal, amlodipin kombinasi telmisartan, amlodipin kombinasi valsartan periode Januari sampai Agustus 2018. Dari hasil penelitian dengan melihat persen penurunan dan waktu penurunan tekanan darah pasien dan efek samping maka dapat disimpulkan bahwa Kombinasi amlodipin dan telmisartan paling efektif di antara amlodipin tunggal dan amlodipin kombinasi valsartan dalam menurunkan hipertensi pada pasien gagal ginjal kronik . Efek samping yang ditimbulkan dari kelompok amlodipin dalah adalah udem sebanyak 7,14\%, efek samping yang ditimbulkan dari kelompok amlodipin kombinasi Telmisartan adalah hiperkalemia sebanyak 14,28 \%, dan efek samping yang ditimbulkan oleh kelompok amlodipin kombinasi valsartan adalah pusing sebanyak 14, $28 \%$

\section{PENDAHULUAN}

Gagalginjalkronik (GGK) adalahpenyakitginjal yang ditandai dengan penurunan fungsi ginjal yang progresif, yang pada akhirnya menyebabkan kerusakan struktural pada nefron yang ireversibel, minimal selama 3 bulan dengan atau tanpa adanya kerusakan pada ginjal. Estimasi tingkat filtrasi glomerulus (eGFR) berkisar antara $90 \mathrm{~mL} /$ menit / 1,73 m2 pada tahap awal sampai $15 \mathrm{~mL}$ / menit / 1,73 m2 pada tahap akhir penyakit. Kerusakan ginjal ditandai dengan kelainan patologis atau tanda cedera, termasuk kelainan pada tesdarah atau urin (1)

Menurut Seventh Report of the Joint National Commite of Prevention, Detection, Evaluation, and Treatment of High Blood Pressure (JNC-7), Pilihan utama Obat antihipertensi pada pasien gagal ginjal kronik adalah ACEI dan ARB (2). Namun penelitian yang dilakukan di Rumah sakit Kandow periode juni sampai juli 2014 menunjukkan bahwa obat yang paling banyak digunakan pada pasien Gagal Ginjal Kronik, Pada kelompok terapi tunggal, golongan Calsium Channel Blocker (CCB) sebanyak 14 pasien (58,3\%), golongan Diuretik sebanyak 8 pasien $(33,3 \%)$ dan golongan ACE-I sebanyak 2 pasien $(8,3 \%)$ (3). Selain itu dengan penelitian yang dilakukan di Rumah sakit Universitas Hasanuddin periode bulan Januari hingga Desember 2015 menunjukkan bahwa obat yang paling banyak diresepkan adalah golongan amlodipin $41 \%$, furosemid (21\%) dan Irbesartan $(13 \%)$ (4). penelitian sebelummnya juga melaporkan bahwa obat yang paling banyak diresepkan pada pasien CKD adalah golongan CCB $74,16 \%$, Diuretik 40\%, beta blockers 30\%, alpha bloker 19,17\%, ACEI 1,6\%, ARB dan sentral akting simpatolitik $10 \%$,vasodilator $1,67 \%$, .Golongan CCB yang paling umum digunakan adalah Amlodipin 50\%, cilnidipine 17,5\% dan 6,7\% nifedipin (5).

Hasil penelitian di atas hanya mendata penggunaan obat antihipertensi yang digunakan oleh pasien gagal ginjal kronik namun efektivitas golongan CCB (amlodipin) sebagai antihipertensi yang paling umum digunakan pada pasien gagal ginjal kronik belum diteliti .

Dari penelitian sebelummnya pengggunaan obat antihipertensi tunggal pada gagal ginjal hemodialisa adalah amlodipin sebanyak $80 \%$ dan kombinasi terbanyak adalah golongan CCB dan ARB adalah $9 \%$ (6).

Oleh karena itu Telah dilakukan Penelitian untukmenganalisis efektivitas penggunaan antihipertensi amlodipin tunggal dan kombinasi amlodipin dan ARB pada pasien gagal ginjal kronik selamarawatinap di RSUP Dr. Wahidin Sudirohusodo Makassar.

\section{METODE PENELITIAN}

\section{Rancangan Penelitian}

Jenis penelitian bersifat observasional non ekperimental dengan dan pengambilan data dilakukan secara retrospektif. Jenis data penelitian adalah profil pengobatan antihipertensi pada pasien gagal ginjal kronik rawat inap di RSUP Dr. Wahidin Sudirohusodo Makassar 


\section{Lokasi dan Waktu Penelitian}

Penelitian dilaksanakan pada periode bulan september sampai oktober 2018. dan lokasi penelitiandi instalasi rekam medik Rumah Sakit Dr. Wahidin Sudirohusodo Makassar.

\section{Bahan Penelitian}

Bahan penelitian ini dilakukan terhadap pasien yang mengalami gagal ginjal kronik yang telah di RSUP Dr. Wahididn Sudirohusodo Makassar selama periode JanuariAgustus 2018 menggunakan alat bantu berupa data rekam medik

\section{Prosedur Kerja}

Pasien gagal ginjal kronik rawat inap di RSUP.Dr. Wahididn Sudirohusodo dengan Kriteria inklusi: Pasien dengan gagal ginjal kronik tahap akhir atau ESRD, Pasien yang mendapatkan terapi obat antihipertensi amlodipin tunggal dan kombinasi amlodipin dan ARB, memiliki catatan rekam medik dan dapat terbaca, Pasien dengan Tekanan darah awal sistol dan diastole $>140 / 90 \mathrm{mmHg}$.

\section{HASIL DAN PEMBAHASAN}

Rata-rata penurunan Tekanan darah sampel kelompok amlodipin $10 \mathrm{mg}$ pada hari pertama yaitu untuk sistol sekitar 25,28mmHg dan untuk diastol 12,42 mmHg. Pada hari ke-2 rata rata penurunan tekanan darah sistol yaitu sekitar 22,78 mmHg dan diastol $12,71 \mathrm{mmHg}$. pada hari ke-3 rata-rata penurunan tekanan darah sistol yaitu sekitar 25,42 $\mathrm{mmHg}$ dan untuk diastol sebesar 15,07 mmHg. Pada hari ke 4 rata rata penurunan tekanan darah untuk sistol sekitar 28,42 mmHg dan untuk diastol 13, $5 \mathrm{mmHg}$.

\begin{tabular}{cccc}
$\begin{array}{c}\text { Tabel 1. Penurunan } \\
\text { Amlodipin kombinasiTelmisartan, }\end{array}$ & $\begin{array}{c}\text { Tekanah } \\
\text { Amlodipin kombinasi Valsartan }\end{array}$ \\
\hline \multirow{2}{*}{ Obat } & $\begin{array}{c}\text { Pengukuran } \\
\text { Tekanan Darah }\end{array}$ & $\begin{array}{r}\text { Rata-rata penurunan tekanan } \\
\text { darah (mmHg) }\end{array}$ \\
& Sistol & Diastol \\
\hline \multirow{2}{*}{ Amlodipin 10} & Hari ke-1 & 25,28 & 12,42 \\
mg & Hari ke-2 & 22,78 & 12,71 \\
& Hari ke-3 & 25,42 & 15,07 \\
& Hari ke-4 & 28,42 & 13,5 \\
\hline Amlodipin 10 & Hari ke -1 & 19,28 & 8,85 \\
mg + & Hari ke -2 & 20,57 & 7,71 \\
Telmisartan 80 & Hari ke -3 & 21,85 & 9,42 \\
mg & Hari ke 4 & 22,57 & 12,42 \\
\hline \multirow{2}{*}{ Amlodipin 10} & Hari ke -1 & 31,85 & 21,85 \\
mg + Valsartan & Hari ke -2 & 31,42 & 20 \\
80 mg & Hari ke -3 & 34,28 & 20,71 \\
& Hari ke 4 & 35,57 & 21,85
\end{tabular}

Rata rata penurunan Tekanan darah sampel kelompok amlodipin $10 \mathrm{mg}$ dan telmisartan $80 \mathrm{mg}$ pada hari pertama yaitu untuk sistol sekitar 19,28 $\mathrm{mmHg}$ dan diastol 8,85 mmHg.pada hari ke -2 rata rata penurunan tekanan darah untuk sistol yaitu 20,57 mmHg dan diastol 7,71 mmHg. pada hari ke-3 rata rata penurunan tekanan darah sistol yaitu sebesar 21,85 mmHg dan untuk diastol sebesar 9,42 mmHg. Pada hari ke-4 rata rata penurunan tekanan darah untuk sistol sebesar 22,57 mmHg dan untuk diastol sebesar 12,42 $\mathrm{mmHg}$.

Rata rata penurunan Tekanan darah sampel kelompok amlodipin $10 \mathrm{mg}$ dan valsartan $80 \mathrm{mg}$ pada hari pertama yaitu untuk sistol sekitar 31,85 mmHg dan diastol 21,85 mmHg. pada hari ke-2 rata rata penurunan tekanan darah untuk sistol yaitu sebesar 31,42 mmHg dan diastol sebesar $20 \mathrm{mmHg}$. pada hari ke-3 rata rata penurunan tekanan darah sistol yaitu sebesar $34,28 \mathrm{mmHg}$ dan untuk diastol sebesar 20,71 mmHg.pada hari ke-4 rata rata penurunan tekanan darah untuk sistol sebesar 35,57 $\mathrm{mmHg}$ dan untuk diastol sebesar 21,85 $\mathrm{mmHg}$.
Jumlah pencapaian target pada kelompok amlodipin $10 \mathrm{mg}$ pada hari ke-1 untuk sistol dan diastol sekitar 92,85\% dan $78,57 \%$. Jumlah pencapaian target pada hari ke- 2 untuk sistol dan diastol adalah sekitar 78,57 dan 92,85. Jumlah pencapaian target tekanan darah pada hari ke-3 untuk sistol dan diastol adalah $100 \%$ dan 92,85\%. Jumlah pencapaian target tekanan darah pada hari ke-4 untuk sistol dan diastol adalah $92,85 \%$ dan $85,71 \%$.

Tabel 2. Pencapaian Target Tekanan Darah kelompok Amlodipin dan Amlodipin kombinasiTelmisartan, Amlodipin kombinasi Valsartan

\begin{tabular}{|c|c|c|c|}
\hline \multirow[t]{2}{*}{ Obat } & \multirow{2}{*}{$\begin{array}{l}\text { Pengukuran } \\
\text { Tekanan Darah }\end{array}$} & \multicolumn{2}{|c|}{$\begin{array}{c}\text { Persentasi Pencapaian target tekanan } \\
\text { darah }<140 / 90 \mathrm{mmHg}(\%)\end{array}$} \\
\hline & & Sistol & Diastol \\
\hline \multirow{4}{*}{$\begin{array}{l}\text { Amlodipin } \\
10 \mathrm{mg}\end{array}$} & Hari ke-1 & 92,85 & 78,57 \\
\hline & Hari ke-2 & 78,57 & 92,85 \\
\hline & Hari ke-3 & 100 & 92,85 \\
\hline & Hari ke-4 & 92,85 & 85,71 \\
\hline \multirow{4}{*}{$\begin{array}{c}\text { Amlodipin } \\
10 \mathrm{mg}+ \\
\text { Telmisaratan } \\
80 \mathrm{mg}\end{array}$} & Hari ke -1 & 100 & 100 \\
\hline & Hari ke -2 & 100 & 100 \\
\hline & Hari ke -3 & 100 & 100 \\
\hline & Hari ke 4 & 85,71 & 100 \\
\hline \multirow{4}{*}{$\begin{array}{c}\text { Amlodipin } \\
10 \mathrm{mg}+ \\
\text { Valsartan } 80 \\
\mathrm{mg}\end{array}$} & Hari ke -1 & 57,14 & 100 \\
\hline & Hari ke -2 & 71,42 & 100 \\
\hline & Hari ke -3 & 85,71 & 100 \\
\hline & Hari ke 4 & 100 & 100 \\
\hline
\end{tabular}

Tabel 3. Pencapaian Target Tekanan Darah kelompok Amlodipin dan Amlodipin kombinasiTelmisartan, Amlodipin kombinasi Valsartan

\begin{tabular}{cccc}
\hline $\begin{array}{c}\text { Obat } \\
\text { Antihiperensi }\end{array}$ & Efek Samping & $\begin{array}{c}\text { Jumlah Pasien } \\
\text { Yang } \\
\text { Mengalami } \\
\text { Efek Samping }\end{array}$ & $\begin{array}{c}\text { Persentase } \\
\text { pasien yang } \\
\text { mengalami efek } \\
\text { samping }\end{array}$ \\
\hline Amlodipin & Udema & 1 & $7,14 \%$ \\
$\begin{array}{c}\text { Amlodipin }+ \\
\text { Telmisartan } \\
\text { Amlodipin }+ \\
\text { Valsartan }\end{array}$ & Hiperkalemia & 1 & $14,28 \%$ \\
\hline
\end{tabular}

Dari 28 pasien gagal ginjal kronik yang dirawat di rumah sakit, terdapat 3 pasien yang mengalami efek samping penggunaan antihipertensi. Diantaranya pemberian amlodipin memiliki efek samping udem sebanyak 1 pasien $(7,14 \%)$, Pusing sebanyak 1 pasien $(14,28 \%)$ dan efek samping telmisartan yaitu hiperkalemia sebanyak 1 pasien $(14,28 \%)$

Dari hasill penelitian, diperoleh bahwa kelompok valsartan kombinasi amlodipin memiliki rata rata penurunan tekanan darah yang besar baik sistol dan diastolnya. Namun, penggunaan obat antihipertensi secara oral yang dapat menurunkan tekanan darah yang cepat bukan tanpa risiko dan dapat menyebabkan hipotensi dan morbiditas selanjutnya (1). Angka kematian yang lebih tinggi terkait dengan tekanan darah rendah pada CKD kemudian dapat menyebabkan kematian yang terkait dengan penyakit kardiovaskular melebihi risiko kematian yang terkait dengan tekanan darah tinggi. (7)

Dari hasil penelitian diperoleh hasil bahwa kelompok amlodipin kombinasi telmisartan memiliki peurunan tekan darah yang rendah. dan pengurangan tekanan darah yang aman dapat terjadi lebih lambat selama 24 hingga 48 jam. (1)

Dari hasil penelitian, penurunan tekanan darah Telmisartan $80 \mathrm{mg}$ lebih baik daripada valsartan $80 \mathrm{mg}$ dalam mengurangi tekanan darah. Hasil ini disebabkan waktu paruh plasma telmisartan yang lebih lama atau potensi yang lebih tinggi dibandingkan dengan valsartan. (8)

Amlodipin telah terbukti ditoleransi dengan baik pada gangguan ginjal dan waktu paruh pada pasien gagal ginjal tidak mengalami perubahan,sehingga amlodipin sekali sehari dapat digunakan untuk semua derajat fungsi ginjal dan penyesuaiandosistidakperlukan. Calcium Channel Blockers 
adalah obat antihipertensi yang paling umum diresepkan pada pasien hemodialisis. Calcium channel blockers memiliki farmakokinetik yang tidak berubah pada pasien dengan ESRD pada hemodialisis. (9)

Telmisartan adalah antagonis reseptor angiotensin II nonpeptida AT1. Pengikatan ini mencegah angiotensin II dari pengikatan kereseptor sehingga menghalangi vasokonstriksi dan efeksekresialdosterondari angiotensin II (10). Peningkatan kadar kalium dapat terjadi, hal ini disebabkan karena Antagonis reseptor angiotensin II mengurangi kadar aldosteron, yang menghasilkan retensi kalium (11).

Edema dari CCB, terutama dihydropyridine adalah efek vasodilatasi arteri perifer yang kuat. (1). Etiologinya berhubungan dengan penurunan arteriolar resistensi yang tidak tertandingi dalam sirkulasi vena. Perubahan resistensi yang tidak proporsional ini meningkatkan tekanan hidrostatik dalam sirkulasi precapillary dan memungkinkan cairan bergeser ke kompartemnen interstitial (12).

Amlodipin bekerja dengan menghambat influx kalsium sepanjang membran sel dengan menghambat bchannel tipe $\mathrm{L}$ yang menyebabkan vasodilatasi coroner dan perifer, (13). efek samping pusng disebabkan efek vasodilatasi setelah penggunaan obat tersebut (14).

Keterbatasan dan kelemahan dari penelitian adalah metode penelitian retrospektif sehingga tidak dapat mengetahui kondisi pasien yang sebenarnya untuk mengevaluasi efek samping obat. Tetapi karna penelitian iniadalah retrospektif maka efeksamping tidak dapat diketahui dari kondisi pasien secara lengkap Saran penelitian selanjutnya dilakukan dengan metode prospektif dan evaluasi penggunaan obat berdasarkan kondisi pasien.

\section{KESIMPULAN}

Dari hasil penelitian dengan melihat persen penurunan dan waktu penurunan tekanan darah pasien dan efek samping maka dapat disimpulkan bahwa Kombinasi amlodipin dan telmisartan paling efektif di antara amlodipin tunggal dan amlodipin kombinasi valsartan dalam menurunkan hipertensi pada pasien gagal ginjal kronik. Efek samping yang ditimbulkan dari kelompok amlodipin dalah adalah udem sebanyak $7,14 \%$, efek samping yang ditimbulkan dari kelompok amlodipin kombinasi Telmisartan adalah hiperkalemia sebanyak 14,28\%, dan efek samping yang ditimbulkan oleh kelompok amlodipin kombinasi valsartan adalah pusing sebanyak $14,28 \%$

\section{DAFTAR PUSTAKA}

1. Koda-Kimble, Mary Anne., Lloyd yee young., and Brian K.A.. 2013. Applied therapeutics. The Clinical Use Drugs 10th Ed. USA: Philadelphia

2. Chobanian, A.V., Bakris, G.L., Black, H.R., Cushman, W.C., Green, L.A., Izzo Jr, J.L., Jones, D.W., Materson, B.J., Oparil, S., Wright Jr, J.T. and Roccella, E.J., 2003. Seventh report of the joint national committee on prevention, detection, evaluation, and treatment of high blood pressure. hypertension,42(6), pp.1206-1252

3. Muchtar, N.R., 2015. Studipenggunaanobatantihipertensi pada pasiengagalginjalkronik yang menjalaniperawatan di RSUP Prof. Dr. RD Kandou Manado periodeJuli 2013-Juni 2014. PHARMACON, 4(3), pp.2228.

4. Suardi, M. D., 2017. Identifkasi Drug Related Problem Terhadap Penggunaan Obat Antihipertensi Pada Pasien Gagal Ginjal Kronik Di salah Satu Rumah Sakit Di Makassar. Makassar: UNHAS

5. Joseph, N., Yogananda,R., Bharathi, Padman, V., Sandeep, 2017. A Study On Prescription Pattern of Antihypertensive Agents in Chronic Renal Failure Patients and Assessment of Medication Adherence.InternationalJurnal of Pharmaceutical Sciences Review and Research, 45(2),pp.72-75.

6. .Kusumawati, A.H., Amalia, L., Gondodiputro, R.S. and Rahayu, C., 2017. PengaruhPemberianObatAntihipertensiTerhadapKualitasHidupPasienH ipertensiDenganGangguanGinjal Kronik di InstalasiHemodialisaRsup Dr. Hasan Sadikin Bandung. Pharma Xplore: JurnalSains dan Ilmu Farmasi,1(2)

7. Kovesdy, C.P., Trivedi, B.K., Kalantar-Zadeh, K. and Anderson, J.E., 2006. Association of low blood pressure with increased mortality in patients with moderate to severe chronic kidney disease. Nephrology Dialysis Transplantation, 21(5), pp.1257-1262

8. Littlejohn, T., Mroczek, W., Marbury, T., VanderMaelen, C.P. and Dubiel, R.F., 2000. A prospective, randomized, open-label trial comparing telmisartan $80 \mathrm{mg}$ with valsartan $80 \mathrm{mg}$ in patients with mild to moderate hypertension using ambulatory blood pressure monitoring. The Canadian journal of cardiology,16(9), pp.1123-1132

9. Ahmad, R., Habib, A. and Rehman, S., 2016. Management of hypertension in patients with end-stage renal disease leading to haemodialysis: a challenge. International Journal of Advances in Medicine, 3(4), pp.790798.

10. Lacy C.F. and Lora L Amstrong., . 2009. Drug Information Handbook ${ }^{17}$ th Edition. American Pharmacist Asosiation. Amerika

11. Baxer, Karen .2010.Stockley's Drug Ineractions. Pharmaceuical Press is he publishing Division of he Royal Pharmaceuical Society of Grea Britain

12. Sica, D.A., 2003. Calcium channel blocker-related peripheral edema: can it be resolved?. The Journal of Clinical Hypertension, 5(4), pp.291-295

13. Fauci and Longo. 2008. Harrison's principles of Internal Medicine Seventeenth Edition.The McGraw-Hill Companies, Inc. USA

14. American Heart Association-America Stroke Association. 2016. Heart Disease and Stroke Statitistic. AHA National Center 